\title{
The effectiveness of BMI, calf circumference and mid-arm circumference in predicting subsequent mortality risk in elderly Taiwanese
}

\author{
Alan C. Tsai ${ }^{1,2 *}$ and Tsui-Lan Chang ${ }^{3}$ \\ ${ }^{1}$ Department of Healthcare Administration, Asia University, 500 Liufeng Road, Wufeng, Taichung 41354, Taiwan \\ ${ }^{2}$ Department of Health Services Management, School of Public Health, China Medical University, Taichung, 404 Taiwan \\ ${ }^{3}$ Hsin Yung Ho Hospital, Taoyuan, Taiwan \\ (Received 12 February 2010 - Revised 4 August 2010 - Accepted 5 August 2010 - First published online 6 December 2010)
}

\section{Abstract}

BMI, mid-arm circumference (MAC) and calf circumference (CC) are anthropometric indicators often included in geriatric health measurement scales. However, their relative effectiveness in predicting long-term mortality risk has not been extensively examined. The present study aimed to evaluate the relative effectiveness of these anthropometrics in predicting long-term mortality risk in older adults. The study prospectively analysed the ability of these indicators in predicting 4-year follow-up mortality risk of a population-representative sample of 4191 men and women, 53 years of age or older in the 'Survey of Health and Living Status of the Elderly in Taiwan'. Cox regression analyses were performed to evaluate the association of follow-up mortality risk with low $\left(<21 \mathrm{~kg} / \mathrm{m}^{2}\right)$ or high $\left(\geq 27 \mathrm{~kg} / \mathrm{m}^{2}\right)$ BMI, low MAC $(<23 \cdot 5 / 22 \mathrm{~cm}$ for men/women) and low CC $(<30 / 27 \mathrm{~cm})$ respectively, according to Taiwanese-specific cut-off points. Results showed that low CC and low MAC were more effective than low BMI in predicting follow-up mortality risk in 65-74-year-old elderly. But low CC and low BMI were more effective than low MAC in $\geq 75$-year-old elderly, and low BMI was more effective than low MAC or low CC in 53-64-year-old persons. High BMI was not effective in predicting mortality risk in any of these age ranges. These results suggest that in elderly adults, $\mathrm{CC}$ is more effective than BMI in predicting long-term mortality risk. Thus, more consideration to CC and MAC in designing geriatric health or nutritional measurement scales is recommended.

Key words: BMI: Mid-arm circumference: Calf circumference: Mortality risk

Extreme body weight, either excessive or inadequate, possesses health risk. Excessive body weight or obesity is a major risk factor of hypertension, dyslipidaemia, type 2 diabetes and heart disease, whereas underweight is often associated with weakened immune competency, increased risk of infection and poor physical functional ability ${ }^{(1-3)}$. Weight change is also associated with changes in the extremities such as mid-arm circumference (MAC) and calf circumference (CC). Many factors such as ageing, physical activity, nutrition and chronic health conditions can influence the size of these circumferences ${ }^{(4)}$.

BMI $\left(\mathrm{kg} / \mathrm{m}^{2}\right)$, calculated from height and weight, is usually considered an indicator of body fatness because weight gain is usually associated with fat gain. MAC and CC reflect body muscle mass in addition to subcutaneous fat, thus are indicative of physical functional ability and body fatness ${ }^{(5)}$.

Advanced ageing is often accompanied by unplanned weight loss and body protein loss, a process called sarcopenia, which is often associated with functional decline ${ }^{(6)}$.
Thus, excessive weight loss rather than excessive weight gain is more of a concern in geriatric health. Monitoring changes in weight (or BMI) and circumferences of extremities such as arm and calf, therefore, is particularly useful in geriatric care.

Because BMI, MAC and CC can reflect weight loss and functional decline in older adults, these indicators have been included in scales for assessing health or nutritional status of frail or hospitalised persons ${ }^{(7)}$. However, the relative ability of these indicators in predicting functional status or long-term mortality has not been extensively examined, especially in Eastern populations. In the present study, we compared the ability of BMI, MAC and CC in predicting long-term mortality risk in older Taiwanese.

\section{Methods}

The present study analysed the 1999 and 2003 data of the 'Survey of Health and Living Status of the Elderly in Taiwan', a population-representative longitudinal cohort

Abbreviations: CC, calf circumference; MAC, mid-arm circumference.

*Corresponding author: A. C. Tsai, fax +188642332 1206, email atsai@umich.edu 
study conducted by the Bureau of Health Promotion of the Department of Health of Taiwan. This ongoing cohort study was initiated in 1989 for gaining an understanding of the role of socioeconomic, environmental, lifestyle and health care parameters on health, wellbeing and quality of life of older Taiwanese ${ }^{(8)}$. The design and sampling process of the project are available at a government website $^{(9)}$, and the key steps are outlined in Fig. 1. The study employed a multi-stage national probability sampling process. The entire population in Taiwan was first stratified into 361 administrative units (primary sampling units). After excluding thirty lightly populated mountainous (aboriginal) areas, the remaining 331 primary sampling units were stratified into twenty-seven strata of roughly equal population sizes, and fifty-six primary sampling units were chosen based on proportion-to-size random selections. Stage 2 involved proportion-to-size selections of blocks (lins, the primary administrative unit) from selected primary sampling units, and the final stage involved random selections of two eligible persons, 60 years of age or older, from each of the selected lins. The process selected 4412 elderly men and women $\geq 60$ years of age to serve as subjects.

In 1996, a second sampling of 2462 subjects, 50-66 years old, selected with the same process was added to the cohort. Subjects in the cohort were interviewed every 3-4 years (in 1989, 1993, 1996, 1999, 2003 and 2006) with a core questionnaire. Each survey also contained additional questionnaires for specific purposes. Data up to the 2003 survey have been released for academic studies.

In each survey, trained interviewers conducted in-home face-to-face interviews. The 1999 survey involved all available (4915) participants in the cohort, and the youngest was 53 years old. Only the 1999 survey included data of all the three (BMI, MAC and CC) anthropometric measurements and therefore was chosen as the baseline dataset of the present analysis. The 2003 survey, the latest dataset available, served as an end point. Data were analysed with the Statistical Package for the Social Sciences (SPSS version 14.0; Chicago, IL, USA). Self-reported height and weight at

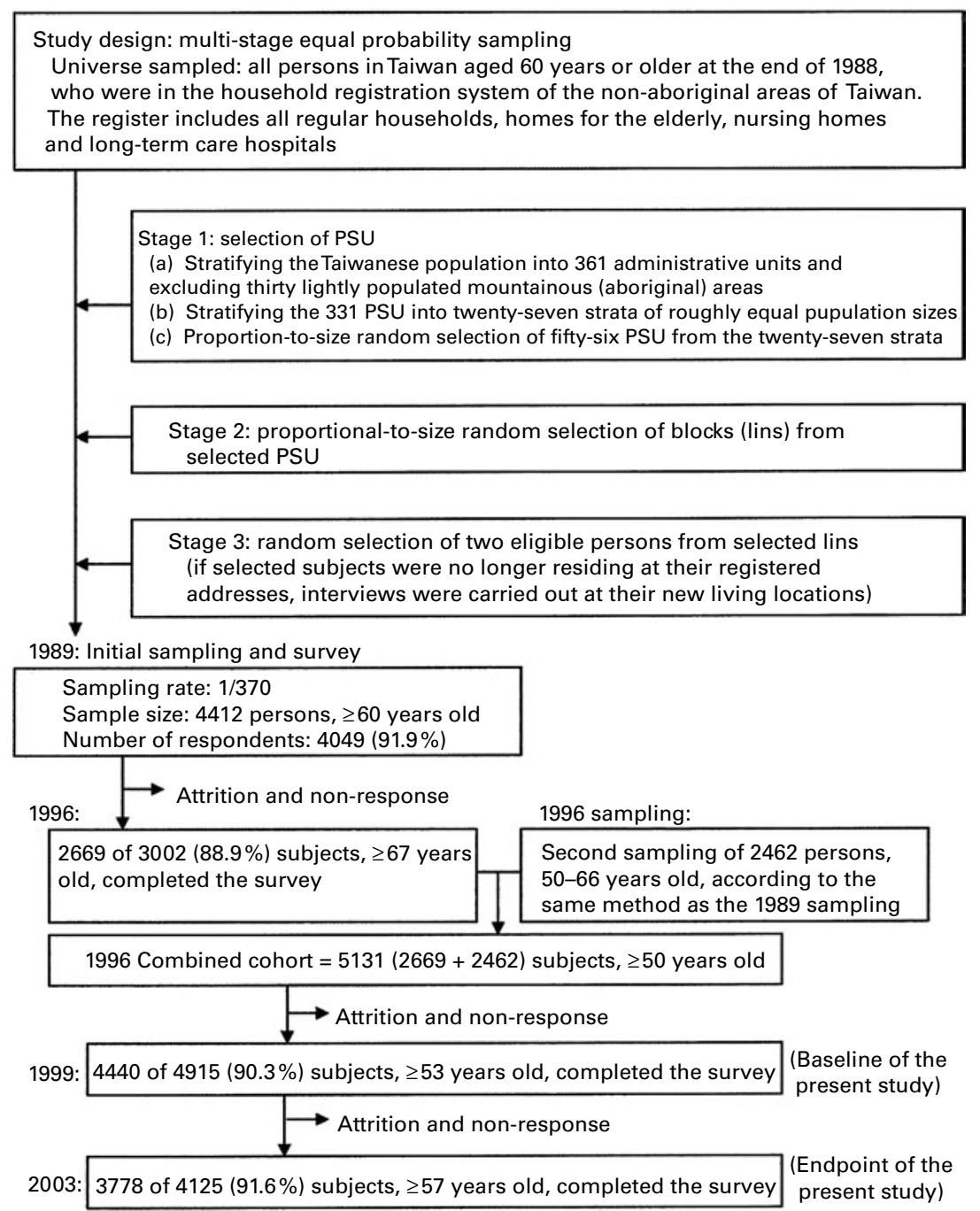

Fig. 1. Sampling process of the Survey of Health and Living Status of the Elderly in Taiwan. PSU, primary sampling units. 
baseline (1989) were used to calculate BMI $\left(\mathrm{kg} / \mathrm{m}^{2}\right)$. MAC and CC were measured. Population-specific cut-off points were used to define low or high anthropometric values. The present analysis used the higher threshold values of the anthropometric cut-off points in the Mini Nutritional Assessment Taiwan Version-II ${ }^{(10)}$. The cut-off points were $<21 \mathrm{~kg} / \mathrm{m}^{2}$ for low BMI and $\geq 27 \mathrm{~kg} / \mathrm{m}^{2}$ for high BMI for both men and women, and $23.5 / 22 \mathrm{~cm}$ (for men/ women) for low MAC and $30 / 27 \mathrm{~cm}$ (for men/women) for low CC. No cut-off points was established for high extremities. Mortality data were collected from records maintained by the Survey of Health and Living Status of the Elderly in Taiwan and confirmed with records of the Universal Health Insurance Program and the National Household Registration. Age-, sex-, smoking status- and routine physical activity-adjusted 4-year follow-up survival curves classified according to BMI, MAC and CC statuses for subjects aged 53-64, 65-74 and $\geq 75$ years are shown in Figs. 2-4, respectively. The study was conducted according to the guidelines laid down in the Declaration of

(a)

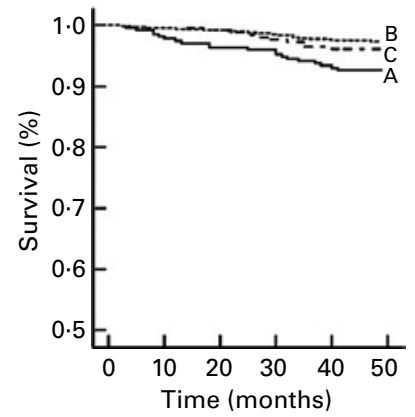

(b)

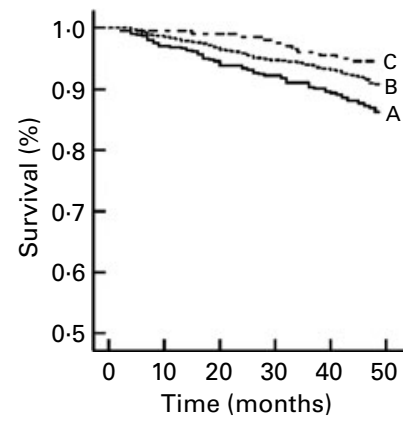

(c)

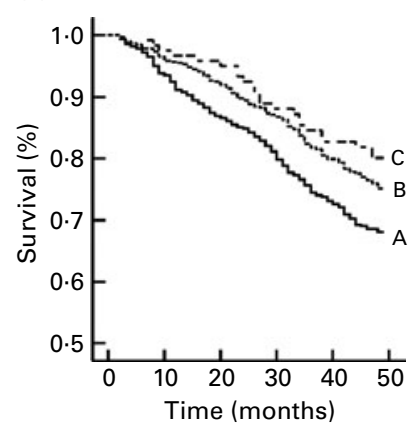

Fig. 2. Age-, sex- and smoking status-adjusted 4-year follow-up survival curves stratified by BMI status $\left(-,<21 \mathrm{~kg} / \mathrm{m}^{2} ;---, 21-27 \mathrm{~kg} / \mathrm{m}^{2}\right.$; $-\cdot-, \geq 27 \mathrm{~kg} / \mathrm{m}^{2}$ ) and age range (53-64 years (a), 65-74 years (b), $\geq 75$ years (c)). Cox regression analyses (adjusted for age, sex, exercise and smoking status) showed that underweight $\left(<21 \mathrm{~kg} / \mathrm{m}^{2}\right)$ was associated with higher follow-up mortality risk. Hazard ratio (adjusted OR) and $95 \% \mathrm{Cl}$ were $2.79(1.58,4.95)$ for $53-64$ years, $1.54(1.12,2.13)$ for $65-74$ years and $1.38(1.10,1.74)$ for $\geq 75$ years elderly (all $P<0.01$ ), using elderly normal weight $\left(21-27 \mathrm{~kg} / \mathrm{m}^{2}\right)$ as the reference. Excessive weight $\left(\geq 27 \mathrm{~kg} / \mathrm{m}^{2}\right)$ was not significantly associated with mortality risk. The HR and $95 \% \mathrm{Cl}$ were $1.45(0.70,2.98)$ for $53-64$ years, $0.58(0.31,1.08)$ for $65-74$ years and $0.78(0.50,1.21)$ for $\geq 75$ years elderly, (all $P>0.05)$ using subjects with desirable weight $\left(21-27 \mathrm{~kg} / \mathrm{m}^{2}\right)$ as the reference.

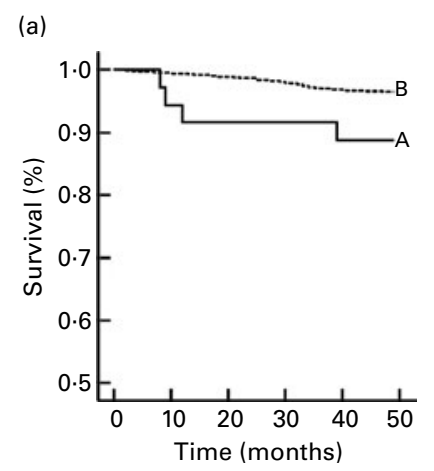

(b)
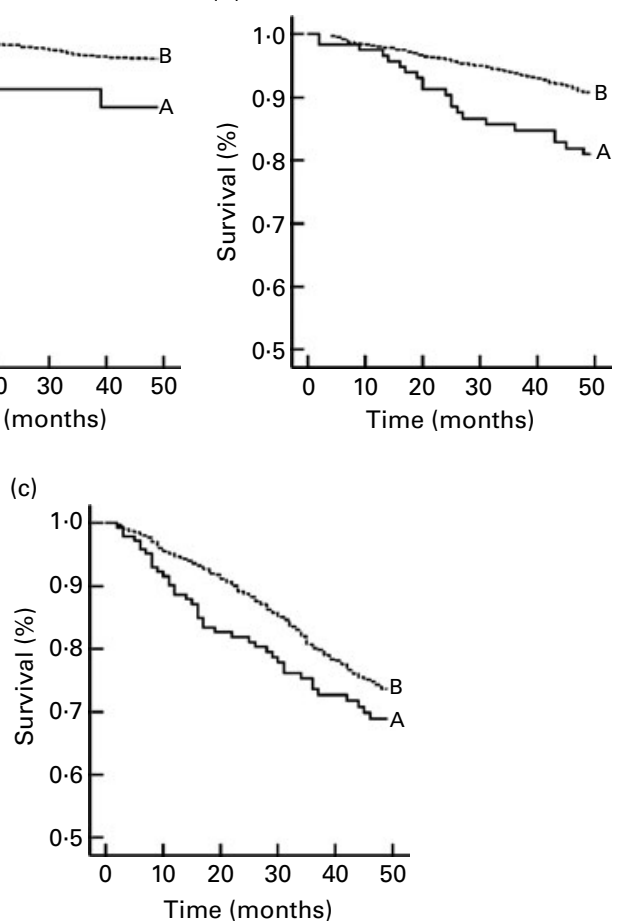

Fig. 3. Age-, sex- and smoking status-adjusted 4-year follow-up survival curves stratified by size of mid-arm circumference (MAC) $(<23.5 \mathrm{~cm}$ for men/22 cm for women (-) or $\geq 23.5 / 22 \mathrm{~cm} \mathrm{(--))} \mathrm{and} \mathrm{age} \mathrm{range} \mathrm{(53-64} \mathrm{years}$ (a), 65-74 years (b), $\geq 75$ years (c)). Cox regression analyses (adjusted for age, sex, exercise and smoking status) showed that small MAC $(<23.5 / 22 \mathrm{~cm})$ was associated with higher follow-up mortality risk. Hazard ratio (adjusted OR) and $95 \% \mathrm{Cl}$ were $3.39(1.22,9.45)(P<0.05)$ for 53-64 years, $2.19(1.37$, 3.50) $(P<0.001)$ for $65-74$ years and $1.31(0.93,1.84)(P>0.05)$ for $\geq 75$ years elderly using subjects with $M A C \geq 23 \cdot 5 / 22 \mathrm{~cm}$ as the reference.

Helsinki, and all procedures involving human subjects/ patients were approved by the government-appointed representatives. Written informed consent was obtained from all the subjects/patients.

Cox regression analyses were performed to evaluate the relative mortality risks of the subjects with low or high BMI, or low MAC or CC adjusted for age, sex, smoking status and physical activity. Statistical significance for all the analyses was evaluated at $\alpha=0.05$.

\section{Results}

During the 4-year follow-up period, 566 of 4191 respondents died. Mortality risk increased from $4 \%$ for persons aged 53-64 years to 11 and 29\% for persons aged 65-74 and $\geq 75$ years, respectively. In all the three age groups, persons with low BMI $\left(<21 \mathrm{~kg} / \mathrm{m}^{2}\right)$, low MAC $(<23.5 /$ $22 \mathrm{~cm}$ for men/women) or low CC $(<30 / 27 \mathrm{~cm}$ for men/ women) had higher mortality risk than persons with normal BMI $\left(21-27 \mathrm{~kg} / \mathrm{m}^{2}\right)$ or circumferences (Tables 1 and 2). Persons with excessive BMI $\left(\geq 27 \mathrm{~kg} / \mathrm{m}^{2}\right)$ had higher risk in near-old (53-64 years) persons but had lower risk in older ( $\geq 65$ years) persons compared with persons with normal BMI. 
(a)

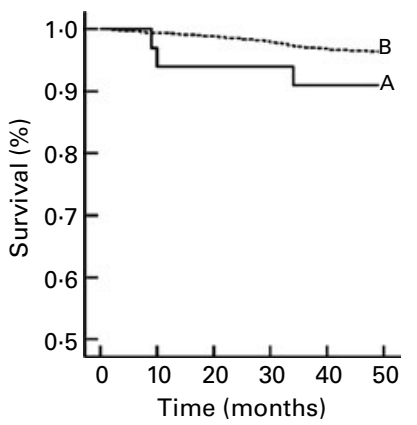

(b)

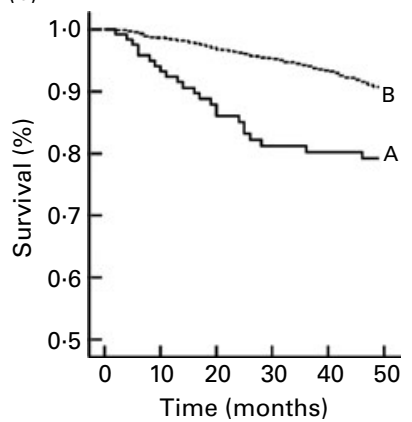

(c)

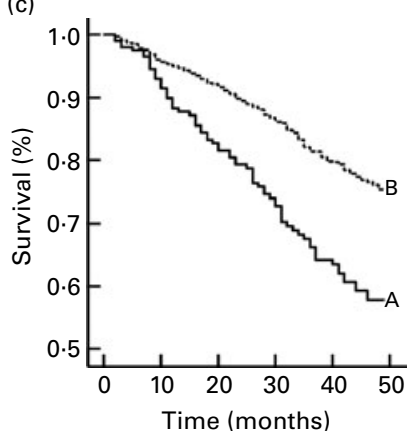

Fig. 4. Age-, sex- and smoking status-adjusted 4-year follow-up survival curves stratified by size of calf circumference (CC) $(<30 \mathrm{~cm}$ for men/27 cm for women (-) or $\geq 30 / 27 \mathrm{~cm} \mathrm{(---))}$ and age range (53-64 years (a), 65-74 years (b), $\geq 75$ years (c)). Cox regression analyses (adjusted for age, sex, exercise and smoking status) showed that small CC $(<30 / 27 \mathrm{~cm})$ was associated with higher follow-up mortality risk. Hazard ratio (adjusted OR) and $95 \% \mathrm{Cl}$ were $2.64(0.82,8.46)(P>0.05)$ for $53-64$ years, 2.59 $(1.66,4.06)(P<0.001)$ for $65-74$ years and $1.98(1.52,2.58)(P<0.001)$ for $\geq 75$ years elderly using subjects with $C C \geq 30 / 27 \mathrm{~cm}$ as the reference.

Cox regression analyses showed that underweight $\left(<21 \mathrm{~kg} / \mathrm{m}^{2}\right)$ significantly increased follow-up mortality risk in all the three age ranges, but the risk was greater (hazard ratio $=2.79) \quad(P<0.001)$ for 53-64-year-old persons than for older persons (hazard ratio $=1.54$ for 65-74-year-old and hazard ratio $=1.38$ for $\geq 75$-year-old persons, both $P<0.01$ ) (Fig. 2). Excessive weight $\left(\geq 27 \mathrm{~kg} / \mathrm{m}^{2}\right)$ appeared to increase the mortality risk in 53-64-year-old persons but to reduce the risk in older ( $\geq 65$ years) persons, but all these changes were not statistically significant (all $P>0 \cdot 05$ ).

Small MAC increased follow-up mortality risk in 53-64-year-old and 65-74-year-old persons, but not in $\geq 75$-year-old elderly using normal MAC as the reference (Fig. 3). Small CC increased follow-up mortality risk in elderly persons (65-74 and $\geq 75$ years) (both $P<0.001$ ) using normal $\mathrm{CC}$ as the reference; but the increase in 53-64-year-old persons was NS (Fig. 4).

\section{Discussion}

Results of the present study suggest that all the three anthropometrics (BMI, MAC and CC) have long-term mortality risk-predicting values in older adults, but their relative effectiveness varies and is dependent on age.

Table 1. Baseline characteristics of 4191 men and women

(Mean values and standard deviations; number and percentage values)

\begin{tabular}{|c|c|c|c|c|}
\hline Parameter & $n$ & $\%$ & Mean & SD \\
\hline \multicolumn{5}{|l|}{ Sex } \\
\hline Men & 2228 & $53 \cdot 2$ & & \\
\hline Women & 1963 & $46 \cdot 8$ & & \\
\hline Age (years) & & & 68.75 & $9 \cdot 13$ \\
\hline $53-64$ & 1490 & $35 \cdot 6$ & & \\
\hline $65-74$ & 1536 & $36 \cdot 6$ & & \\
\hline$\geq 75$ & 1165 & $27 \cdot 8$ & & \\
\hline \multicolumn{5}{|c|}{ Formal education (years) } \\
\hline$<6$ & 1934 & $46 \cdot 2$ & & \\
\hline$\geq 6$ & 2256 & $53 \cdot 8$ & & \\
\hline \multicolumn{5}{|c|}{ Current smoker } \\
\hline Yes & 1022 & $24 \cdot 4$ & & \\
\hline No & 3169 & $75 \cdot 6$ & & \\
\hline \multicolumn{5}{|c|}{ Routine exercise (times/week) } \\
\hline$\leq 2$ & 2005 & $47 \cdot 8$ & & \\
\hline$\geq 3$ & 2185 & $52 \cdot 2$ & & \\
\hline \multicolumn{5}{|l|}{ Height (cm) } \\
\hline Men & & & $164 \cdot 7$ & $6 \cdot 3$ \\
\hline Women & & & $153 \cdot 3$ & $6 \cdot 2$ \\
\hline \multicolumn{5}{|l|}{ Weight (kg) } \\
\hline Men & & & $63 \cdot 1$ & $9 \cdot 7$ \\
\hline Women & & & $55 \cdot 4$ & $9 \cdot 6$ \\
\hline \multicolumn{5}{|l|}{ BMI $\left(\mathrm{kg} / \mathrm{m}^{2}\right)$} \\
\hline Men & & & $23 \cdot 2$ & $3 \cdot 1$ \\
\hline Women & & & $23 \cdot 6$ & 3.7 \\
\hline \multicolumn{5}{|c|}{ Mid-arm circumference $(\mathrm{cm})$} \\
\hline Men & & & $28 \cdot 4$ & 3.5 \\
\hline Women & & & $28 \cdot 0$ & $4 \cdot 0$ \\
\hline \multicolumn{5}{|c|}{ Calf-circumference (cm) } \\
\hline Men & & & $34 \cdot 7$ & $3 \cdot 7$ \\
\hline Women & & & 32.9 & 3.9 \\
\hline
\end{tabular}

Low BMI $\left(<21 \mathrm{~kg} / \mathrm{m}^{2}\right)$ is more effective in predicting mortality risk in near-old (53-64 years) persons than 65-74- or $\geq 75$-year-old elderly. Low MAC predicts increased mortality risk in 53-64- and 65-74-year-old persons but not in $\geq 75$-year-old elderly. Low CC predicts increased follow-up mortality risk in 65-75and $\geq 75$-year-old elderly but not in younger near-old (53-64 years) persons.

In near-old (53-64 years) persons, the utility of MAC and $\mathrm{CC}$ in predicting follow-up mortality risk is limited because only a small proportion ( $1.9 \%)$ of persons have reduced circumferences. Therefore, although these indicators have

Table 2. The follow-up 4-year mortality records (no. of deaths/no. of subjects) in older Taiwanese classified by age and anthropometric statuses ( $n$ 4191)

\begin{tabular}{|c|c|c|c|}
\hline Parameter & $53-64$ years & $65-74$ years & $\geq 75$ years \\
\hline All subjects & $59 / 1490(4 \cdot 0)^{\star}$ & $172 / 1536(11 \cdot 2)$ & $335 / 1165(28 \cdot 8)$ \\
\hline \multicolumn{4}{|l|}{$\mathrm{BMI}\left(\mathrm{kg} / \mathrm{m}^{2}\right)$} \\
\hline$<21$ & $20 / 256(7 \cdot 8)$ & $59 / 352(16 \cdot 8)$ & $147 / 405(36 \cdot 3)$ \\
\hline $21-27$ & $29 / 990(2.9)$ & $102 / 982(10.4)$ & $165 / 636(25.9)$ \\
\hline$\geq 27$ & $10 / 244(4 \cdot 1)$ & $11 / 202(5.4)$ & $23 / 124(18.5)$ \\
\hline \multicolumn{4}{|c|}{ Mid-arm circumference (cm) } \\
\hline$<23.5 / 22 \dagger$ & $4 / 29(13 \cdot 8)$ & $21 / 77(27 \cdot 3)$ & $40 / 97(41 \cdot 2)$ \\
\hline$\geq 23 \cdot 5 / 22$ & $55 / 1461(3 \cdot 8)$ & $151 / 1459(10 \cdot 3)$ & $295 / 1068(27 \cdot 6)$ \\
\hline \multicolumn{4}{|c|}{ Calf circumference $(\mathrm{cm})$} \\
\hline$<30 / 27 \dagger$ & $3 / 29(10.3)$ & $23 / 76(30 \cdot 3)$ & $72 / 143(50 \cdot 3)$ \\
\hline$\geq 30 / 27$ & $56 / 1461(3.8)$ & $149 / 1460(10 \cdot 2)$ & $263 / 1022(25 \cdot 7)$ \\
\hline
\end{tabular}

* Number of deaths in 4 years/total number of subjects in group at baseline. t Cut-off values for men/women. 
high specificity, they have poor sensitivity. In 65-74-yearold persons, MAC and especially CC are more effective in predicting mortality risk than BMI. In $\geq 75$-year-old persons, CC is the most effective, followed by BMI; MAC is not effective.

In the present study, high BMI $\left(\geq 27 \mathrm{~kg} / \mathrm{m}^{2}\right)$ only suggests increased risk in younger (53-64 years) persons and reduced risk in older ( $65-74$ years and $\geq 75$ years) persons; none of these effects reached statistical significance.

The ability of BMI to predict follow-up mortality risk has been observed in numerous studies ${ }^{(11-18)}$. Most studies indicate a J- or U-shaped association, but the thresholds for low and excessive BMI vary among populations or studies. The thresholds generally fall within $\mathrm{BMI}<20-23 \mathrm{~kg} / \mathrm{m}^{2}$ for underweight and $\mathrm{BMI}>25-30$ $\mathrm{kg} / \mathrm{m}^{2}$ for excessive weight, depending on the age range of study subjects and statistical conditions applied.

Some recent large-scale studies have indicated a positive association of mortality risk with excessive BMI and an inverse association with low BMI. In a recent study involving over half a million 50-71-year-old persons in the USA, Adams et al. ${ }^{(19)}$ observed that the risk of death was associated with both overweight (BMI $25-30 \mathrm{~kg} / \mathrm{m}^{2}$ ) and obesity (BMI $>30 \mathrm{~kg} / \mathrm{m}^{2}$ ) among men and women when the analysis was restricted to healthy people who had never smoked. The Prospective Studies Collaboration ${ }^{(20)}$ which analysed fifty-seven prospective studies involving 900000 adults suggested that mortality was lowest at about $22 \cdot 5-25 \mathrm{~kg} / \mathrm{m}^{2}$; above or below this range, the overall mortality increases. In a national cohort involving 64731 men and 19011 women, Freedman et al. ${ }^{(21)}$ observed that among younger/middle-aged ( $<55$ years) never-smoking women, the risk rose as BMI increased above $21.0 \mathrm{~kg} / \mathrm{m}^{2}$, whereas in older women, the risk increased beginning at a higher BMI $\left(>25.0 \mathrm{~kg} / \mathrm{m}^{2}\right)$. Among younger men who never smoked, the risk began to rise above $23.0 \mathrm{~kg} / \mathrm{m}^{2}$, whereas in older men, the risk did not begin to increase until exceeding $30.0 \mathrm{~kg} / \mathrm{m}^{2}$. In Eastern populations, Tamakoshi et $a l^{(22)}$ observed that all-cause mortality risk is lowest and fairly consistent between BMI 20 and $30 \mathrm{~kg} / \mathrm{m}^{2}$ in both older Japanese men and women aged 65-79 years. Jee et $a l^{(23)}$ indicated a lowest all-cause mortality risk of BMI $23-25 \mathrm{~kg} / \mathrm{m}^{2}$ for Koreans aged 30-90 years. On the other hand, the study by Auyeung et al. ${ }^{(24)}$ indicated that BMI is effective in predicting all-cause mortality risk for underweight $\left(\mathrm{BMI}<21 \mathrm{~kg} / \mathrm{m}^{2}\right)$ males but not for females, and not effective in predicting risk for excessive weight in Chinese people aged 65 years or older in Hong Kong. Taken together, these results suggest that BMI has mortality risk predictive ability, but the thresholds for underweight and excessive weight vary among populations and are age dependent.

Circumferences of the extremities, especially MAC and CC, have been found to be very useful for evaluating health and nutritional statuses of elderly persons ${ }^{(25,26)}$, and these measures can provide valuable information on muscle-related disability, physical function and mortality risk $^{(27,28)}$. Larger circumference of the extremities, especially CC, has been observed to have protective health effects $^{(29,30)}$. An inverse association between upper arm circumference and mortality has previously been observed in males ${ }^{(14)}$ and females ${ }^{(15)}$ of the National Health and Nutrition Examination Survey I and II. An inverse association between upper arm circumference and mortality risk has also been observed in 61-79-year-old men in the British Regional Heart Study ${ }^{(31)}$ after adjusting for multiple indicators of ill health. Because MAC does not decline until the later stage of body functional decline, it has been suggested that it is not as useful in serving as an indicator of nutritional status in younger old as it is in older individuals $^{(32,33)}$. In the Canada Fitness Survey, arm circumference, thigh circumference and CC were significantly protective in men, while arm and thigh circumferences were protective in women ${ }^{(34)}$. It was postulated that these inverse associations between circumferences of the extremities and health risk may be owed to a greater accumulation of subcutaneous lean body mass, adipose tissue or a combination of these factors in the periphery.

Thus, it is clear that in addition to BMI, MAC and CC have good and, in many cases, better follow-up mortality risk-predicting abilities. However, despite of these wellrecognised observations, the predictive ability of these extremities has rarely been directly compared ${ }^{(34)}$, especially examining the relative effectiveness during various stages of the elderly life. To our knowledge, the present study is the first to observe an age-dependent relationship of the relative effectiveness of the three measures in predicting follow-up mortality in elderly persons.

Because these anthropometrics reflect body fatness, physical functioning and health statuses and can predict follow-up mortality risk, these indicators can play an important role in health or nutrition assessment scales. Most health or nutritional assessment tools include some indicators of body weight such as BMI or recent weight changes $^{(7)}$, and only few such as the Mini Nutritional Assessment include MAC and CC in addition to $\mathrm{BMI}^{(35)}$.

Results of the present study lead us to wonder whether BMI should be the preferred or nearly the only anthropometrics included in most of the geriatric assessment tools and whether the same threshold should be applied across the populations. As we have observed, MAC and especially CC are better predictors of follow-up mortality risk than BMI in the elderly. Consideration should be given to include these indicators in the assessment tools in order to achieve the most accurate results. In frail elderly, there are clear advantages in using CC and/or MAC rather than BMI. Compared with weight and height (for computing BMI), CC and MAC are easier and more accessible and time efficient to measure in frail or disabled individuals.

For persons who are non-ambulatory or have difficulty in standing erectly, BMI can be calculated from estimates 
of stature and weight. Stature can be estimated from tibia length or knee height, and weight can be estimated from knee height and $\mathrm{MAC}^{(36-38)}$. However, these estimations require ethnic/race-, age- and sex-specific equations, and measurements of knee height and tibia length may require special devices. The process is generally more involved than in measuring MAC or CC, and the quality of estimates may sometimes be questionable ${ }^{(36)}$. Thus, for the purposes of the present study, computation of BMI using these estimates is not favoured.

There are strengths and limitations in the present study. A major strength is that the dataset is from a prospective cohort study involving a relatively large nationally representative sample, thus results should have good generalisability. However, the sample size is not yet large enough for certain sections such as individuals with BMI $>30 \mathrm{~kg} / \mathrm{m}^{2}$. In the survey, weight and height are self-reports. Selfreported height and weight are generally known to be accurate $^{(10)}$, but some errors or deviations from true values are unavoidable. CC and MAC data were measured, but no follow-up data were available; therefore, we cannot evaluate the effect of changes in body weight or circumferences over time. We adjusted age, sex, smoking status and routine physical activity to minimise the potential confounding effects by these factors, but we cannot rule out other confounding factors.

Results of the present study indicate that three frequently used anthropometric parameters, BMI, MAC and CC, are effective in predicting follow-up mortality risk of older adults, but their abilities are age dependent. Among the three indicators, CC has the strongest predictive ability in elderly over 65 years of age, and MAC also has good predictive ability in 65-74-year-old elderly. BMI is most effective in younger (53-64 years) persons. Considering that CC and MAC are more accessible and easier to measure than BMI, especially in frail or ill persons, effort should be made to increase the use of these indicators in many of the geriatric health or nutritional assessment tools.

\section{Acknowledgements}

The authors wish to thank the Bureau of Health Promotion, Department of Health of Taiwan, for providing the dataset for the present study. The study is supported by a grant from the National Science Council of Taiwan (NSC 97-2320-B-468-003). A. C. T. conceived the idea, directed the study and drafted the manuscript. T.-L. C. performed statistical analyses. Both the authors read, revised and approved the manuscript. Both the authors declare no conflict of interest of any kind involved in the present study.

\section{References}

1. Seidell JC \& Visscher TLS (2000) Body weight and weight change and their health implications for the elderly. Eur $J$ Clin Nutr 54, Suppl. 3, S33-S39.
2. Bales CW \& Ritchie CS (2002) Sarcopenia, weight loss, and nutritional frailty in the elderly. Annu Rev Nutr 22, 309-323.

3. Hickson M (2006) Malnutrition and ageing. Postgrad Med J 82, 2-8.

4. Tsai AC, Liou JC, Chang MC, et al. (2007) Influence of diet and physical activity on aging-associated body fatness and anthropometric changes in older Taiwanese. Nutr Res 27 , $245-251$.

5. Chumlea WC (2006) Is the MNA valid in different populations and across practice settings? J Nutr Health Aging 10, 524-533.

6. Roubenoff R (2000) Sarcopenia and its implications for the elderly. Eur J Clin Nutr 54, Suppl. 3, 40-47.

7. Green SM \& Watson R (2006) Nutritional screening and assessment tools for older adults: literature review. $J$ Adv Nurs 54, 477-490.

8. Taiwan Provincial Institute of Family Planning, Population Studies Center and Institute of Gerontology, University of Michigan (1989) Survey of Health and Living Status of the Elderly in Taiwan: Questionnaire and Survey Design. Comparative Study of the Elderly in Four Asian Countries. Research report no. 1. Ann Arbor, MI: Population Studies Center and Institute of Gerontology.

9. Bureau of Health Promotion, Department of Health, Taiwan (1989) Survey of the Elderly in Taiwan. http://www.bhp. doh.gov.tw/BHPnet/Portal/Them_Show.aspx?Subject=2007 $12270002 \&$ Class $=2 \& \mathrm{No}=200712270015 \quad$ (accessed 27 February 2009).

10. Tsai AC \& Ku PY (2008) Population-specific mini nutritional assessment effectively predicts the nutritional state and follow-up mortality of institutionalized elderly Taiwanese regardless of cognitive status. Br J Nutr 100, 152-158.

11. Stevens J, Cai J, Pamuk ER, et al. (1998) The effect of age on the association between body-mass index and mortality. $N$ Engl J Med 338, 1-7.

12. World Health Organization (2000) Obesity: Preventing and Managing the Global Epidemic. Technical Report Series no. 894. Geneva: World Health Organization.

13. Grabowski DC \& Ellis JE (2001) High body mass index does not predict mortality in older people: analysis of the Longitudinal Study of Aging. J Am Geriatr Soc 49, 968-979.

14. Allison DB, Zhu SK, Plankey M, et al. (2002) Differential associations of body mass index and adiposity with all-cause mortality among men in the first and second National Health and Nutrition Examination Surveys (NHANES I and NHANES II) follow-up studies. Int $J$ Obes Relat Metab Disord 26, 410-416.

15. Zhu S, Heo M, Plankey M, et al. (2003) Associations of body mass index and anthropometric indicators of fat mass and fat free mass with all-cause mortality among women in the first and second National Health and Nutrition Examination Surveys follow-up studies. Ann Epidemiol 13, 286-293.

16. Wandell PE, Carlson AC \& Theobald H (2009) The association between BMI value and long term mortality. Int $J$ Obes 23, 577-582.

17. Orpana HM, Berthelot JM, Kaplan MS, et al. (2009) BMI and mortality: results from a national longitudinal study of Canadian adults. Obesity (Silver Spring) 18, 214-218.

18. Gulsvik AK, Thelle DS, Mowe M, et al. (2009) Increased mortality in the slim elderly: a 42 years follow-up study in a general population. Eur J Epidemiol 24, 683-690.

19. Adams KF, Schatzkin A, Harris TB, et al. (2006) Overweight, obesity, and mortality in a large prospective cohort of persons 50-71 years old. $N$ Engl J Med 355, 763-778.

20. Prospective Studies Collaboration (2009) Body-mass index and cause-specific mortality in 900,000 adults: collaborative analyses of 57 prospective studies. Lancet 373, 1083-1096. 
21. Freedman DM, Ron E, Ballard-Barbash R, et al. (2006) Body mass index and all-cause mortality in a nationwide US cohort. Int J Obesity (Lond) 30, 822-829.

22. Tamakoshi A, Yatsuya H, Lin Y, et al. (2009) BMI and all-cause mortality among Japanese older adults: findings from the Japan Collaborative Cohort Study. Obesity (Silver spring) 18, 362-369.

23. Jee SH, Sull JW, Park J, et al. (2006) Body-mass index and mortality in Korean men and women. $N$ Engl J Med 355, 779-787.

24. Auyeung TW, Lee JSW, Leung J, et al. (2009) Survival in older men may benefit from being slightly overweight and centrally obese - a 5-year follow-up study in 4,000 older adults using DXA. J Gerontol A Biol Sci Med Sci 65, 99-104.

25. Bonnefoy M, Jauffret M, Kostka T, et al. (2002) Usefulness of calf circumference measurement in assessing the nutritional state of hospitalized elderly people. Gerontology $\mathbf{4 8}$, $162-169$.

26. Coelho AK, Rocha FL \& Fausto MA (2006) Prevalence of undernutrition in elderly patients hospitalized in a geriatric unit in Belo Horizonte, MG, Brazil. Nutrition 22, 1005-1011.

27. Bonnefoy M, Jauffret M \& Jusot JF (2007) Muscle power of lower extremities in relation to functional ability and nutritional status in very elderly people. $J$ Nutr Health Aging 223-228.

28. Rolland Y, Lauwers-cances V, Cournot M, et al. (2003) Sarcopenia, calf circumference, and physical function of elderly women: a cross-sectional study. $J$ Am Geriatr Soc 51, $1120-1124$.

29. Enoki H, Kuzuya M, Masuda Y, et al. (2007) Anthropometric measurements of mid-upper arm as a mortality predictor for community-dwelling Japanese elderly: the Negoya Longitudinal Study of Frail Elderly (NLS-FE). Clin Nutr 26, 597-604.
30. Reid KF, Naumova EN, Carabello RJ, et al. (2008) Lower extremity muscle mass predicts functional performance in mobility-limited elders. J Nutr Health Aging 12, 493-498.

31. Wannamethee SG, Shaper AG, Lennon L, et al. (2007) Decreased muscle mass and increased central adiposity are independently related to mortality in older men. Am J Clin Nutr 86, 1339-1346.

32. Burden ST, Stoppard E, Shaffer J, et al. (2005) Can we use mid upper-arm anthropometry to detect malnutrition in medical inpatients? A validation study. J Hum Nutr Diet 18, 287-294.

33. Allard JP, Aghdassi E, McArthur M, et al. (2004) Nutritional risk factors for survival in the elderly living in Canadian long-term care facilities. JAGS 52, 59-65.

34. Mason C, Craig CL \& Katzmarzyk PT (2008) Influence of central and extremity circumferences on all-cause mortality in men and women. Obesity 16, 2690-2695.

35. Guigo Y, Vellas BJ \& Garry PJ (1994) The Mini Nutritional Assessment (MNA): A practical assessment tool for grading the nutritional state of elderly patients. In Facts and Research in Gerontology, pp. 15-60 [BJ Vellas, Y Guigoz, PJ Garry and JL Albarede, editors]. Supplement: Nutrition New York: Serdi Publishing Co.

36. Lee RD \& Nieman DC (2003) Assessment of the hospitalized patient. In Nutritional Assessment, 3rd ed., pp. 216-250, Chapter 7 [RD Lea and DC Nieman, editors]. New York: McGraw-Hill.

37. Chumlea WC, Guo SS, Wholihan K, et al. (1998) Stature prediction equations for elderly non-Hispanic white, nonHispanic black, and Mexican-American persons developed from NHANES III data. J Am Diet Assoc 98, 137-142.

38. Cereda E, Bertoli S \& Battezzati A (2009) Height prediction formula for middle-aged (30-55 y) Caucasians. Nutrition (Epublication ahead of print version 24 December 2009). 